\title{
Pascal Quignard: escrever é ouvir a palavra perdida
}

\author{
Ruth Silviano Brandão
}

Pouco lido no Brasil, o escritor francês Pascal Quignard tem uma obra variada que passa pela ficção e pelo que chama de Pequenos tratados, em que a ficção não se separa da reflexão ensaística ${ }^{1}$. Escritor erudito, revisita a literatura clássica, principalmente a literatura romana do século II, produzindo também textos ficcionais e teóricos sobre as artes plásticas e a música. Sobre ele, afirma Chantal Lapeyre-Desmaison, estudiosa de sua obra:

O escritor manifesta um gosto marcado por certos períodos, certas culturas, a Antigüidade romana, mas também a Ásia medieval, o século XVII francês, por exemplo. Nada permite, em princípio, dizer de forma evidente qual seria o traço de união entre essas diferentes épocas, esses diferentes lugares. Sob a aparência do descontínuo, qual seria o fio?*

"(Lapeyre-Desmaison, ChanParis: Flohic, 2001: 11)

Podemos dizer, todavia, que a música e o silêncio estão presentes em toda a sua obra, sendo um desses autores cuja vida está tão ligada ao ato de escrever, que podemos falar de uma vida escrita com a ponta do silêncio e da música. Ele próprio músico, em seu ouvido musical enlaçam-se escrita, silêncio e dor.

Passar pelo silêncio e fazer dele sua vida, por esse ponto a que o escritor sempre volta, é ir a um limite da memória, lugar inaugural de um saber que perpassa sua obra: o saber do perdido, a volta aos lugares inóspitos do vazio, para viver com a despossessão, a partir da aprendizagem da incompletude, da não-totalização, que ele atravessa com o impacto de uma escrita, a dele, que é também o testemunho de algo que existe para além do burburinho e do vozerio desse século dos excessos que aponta para o sucesso ilusório da totalização.

${ }^{1}$ Além dos Petits traités, publicados em dois volumes pela Folio, são exemplos desse tipo de ensaio: La leçon de musique, Le nom sur le bout de la langue, Une gêne technique à l'égard des fragments, La haine de la musique e Rhétorique spéculative. Em 2002, foi publicada pela Grasset a trilogia Dernier royaume: Les ombre errantes, Sur le jadis e Abîmes. 
(Quignard, Pascal. Rhétorique spéculative. Paris: Gallimard, 1995: 125)

(Quignard, Pascal. Le nom sur le bout de la langue. Pa ris: Gallimard, 1993: 28)
Reitera-se na escrita de Quignard a prevalência de algo que se perdeu e que se refaz em seu texto, por meio de um processo de reescrever o perdido sob outras formas. O sentido agudo da perda se torna uma inscrição em sua memória, algo que ele tenta sem cessar recuperar, mas de que resta apenas um traço. Saber da impossibilidade de reconquistar o passado, da falta estrutural da linguagem que a torna incapaz de recuperar o perdido, e que aponta para o fracasso de tudo dizer, torna possível, por outro lado, que o escritor afirme, paradoxalmente, que se "falta uma estrela guia, é preciso seguir fielmente a estrela ausente da linguagem"*.

O primeiro livro que li desse escritor-poeta foi Le nom sur le bout de la langue, que se estrutura de forma heterogênea, com uma primeira parte que funciona como uma espécie de vestíbulo do livro, seguida do relato de uma estranha história saída do folclore da Islândia. Em seguida, lêem-se textos que falam da vida do escritor e sua experiência com o mundo mítico, relido por ele de forma pessoal e lírica.

A primeira história fala de um nome, um nome especial, que não pode ser esquecido, pois é condição da realização do amor. O estranho senhor Heidebic de Hell oferece a Colbrune, jovem apaixonada por Jeune, o alfaiate, uma forma de conquistar seu amor. O mais importante seria o desafio que lhe faz de não esquecer seu nome: Heidebic de Hell, em cujo cerne se ouve a palavra inferno, talvez para dizer que o esquecimento é o inferno, que é a falha da memória que o sujeito passa a vida tentando corrigir. Rasura na memória, pois algo se esqueceu, mas continua presente, ressoando como um sofrimento a que falta a palavra ou o nome possível para dizê-lo, para ancorálo. Este gesto seria a possibilidade de dar âncora à angústia, acolhendo a dor no assoalho da escrita.

Esquecer o nome de Heidebic de Hell é entregar-se a ele, o Senhor do céu e da morte, a quem Colbrune, definhando de amor, recorrera em sua prece, na véspera. "Não esqueça meu nome", diz ele, apresentando-lhe seu desafio, o preço do amor*.

Este conto é seguido, no livro, pelo relato de um acontecimento da infância do autor: um instante rápido, algo vivido em um átimo, mas que passa pelos olhos e o ouvido: a mãe que tenta se lembrar de uma palavra e fica muda, estática como uma estátua. Para ele, uma criança sensível, essa é a experiência da Medusa: nesse momento, afirma, ele viu a Medusa. Medusa ou 
o nada são nomes do real, são nomes de algo tão traumático, que não se consegue simbolizar, não se consegue dizer: faltam palavras que, no entanto, multiplicam-se na impossível tarefa de ir lá, de novo, nessa cena.

O nome ou a palavra faltante marca a escrita de Pascal Quignard, que afirma: "assim como aquele que cai sob o olhar da Medusa transforma-se em pedra, aquele que cai sob o olhar da palavra que falta tem a aparência de uma estátua”**

Aquilo que falta é o que causa o estupor, mas é também o que torna imperativa a escrita, na procura da origem, da coisa literária, daquilo que está antes da palavra e antes de uma ruptura que marca o sujeito como uma ferida, mas propicia que daí brote algo:

A mão que escreve é, antes, uma mão que escava a linguagem que falta, que tateia em direção à linguagem sobrevivente, que crispa, enerva-se, que, desde a ponta dos dedos, mendiga. "Bout", "debout" são palavras recentes tiradas da língua que os guerreiros francos empregavam quando invadiram a Gália. "Bautan” é "bouter", é germinar. Sur le "bout" de la langue: algo germina sem florescer. Algo germina sem vir aos lábios daquele que espia no silêncio. É o broto da floração invisível da língua que permanece debout (em pé) sobre a boca, aquém da mastigação, em suplência ao sopro que a respiração utiliza para manter a vida. Aristóteles dizia: "A palavra é um luxo sem o qual a vida é possível". Um botão brota sobre a boca, como brota sobre as árvores, ou sobre as roupas, ou sobre as faces. Os adolescentes têm razão quando acham feias as espinhas que os desfiguram: eles estão a ponto de perder o rosto para sempre. São os traços de um porvir, no qual a morte vem trazer o testemunho de sua germinação, o aparecimento da terra em que a sexualidade se faz tanática, isto é, genital, como aquilo que brota, que esguicha antes de desfalecer em uma aparência de morte. O rosto pessoal é mais um "si mesmo" que um nome próprio, mesmo que esse rosto pessoal não mantenha mais a vida que a linguagem vem afirmar*.

Idêntica questão está presente nos textos que falam da música e da voz do adolescente que perdeu o cristal da voz feminina, passando por uma mudança que é um efeito da separação do universo materno. Essa perda traz a marca de uma castração e provoca um sentimento de abandono e desespero, mais característico dos homens que das mulheres. Quignard escolhe a palavra francesa mue para falar dessa mudança, o que pode querer dizer "mudança na plumagem das aves, do pêlo ou da pele dos animais e mudança de timbre da voz humana na 
" Quignard, Pascal. La leçon de musique. Paris: Hachette 1987: 6)

"(Quignard, Pascal. La haine de la musique. Paris: Gallimard, 1996: 199)

" (Quignard, Pascal. Tous les matins du monde. Paris: Gallimard, 1991) puberdade, como se a voz sofresse uma rachadura, uma ferida jamais curada". Assim, para o escritor, "as vozes humanas são sonatas que se abrem sobre gritos"*.

É possível pensar no ódio à musica e da música, marcada por essa falha impossível de eliminar, cicatriz presente no próprio cerne de sua produção, para sempre fadada à imperfeição. Criação humana, a música sofre dos impasses da respiração e de seus ritmos, do sopro humano já presente na criança que nasce, traço de sua psyché, de sua alma já rasurada. "A expressão ódio da música expressa a que ponto a música pode se tornar odiosa para aquele que mais a amou"*.

Esse tema volta na perda da voz de Marin Marais, no livro Tous les matins du monde*, que é a história de dois músicos, o aprendizado da música e tudo o que concerne à procura do som inaugural, auroral, que faz parte do percurso do músico, aquele que deve fugir dos ruídos mundanos, das glórias, do poder, para conquistar o silêncio e a solidão inerentes à sua arte.

Desse livro se fez o filme homônimo Todas as manhãs do mundo ${ }^{2}$, um filme que deve ser visto, ouvido e gravado na memória pela beleza dos diálogos, das músicas de Sainte-Colombe, de Marin Marais, de Lully e das imagens cuidadosamente construídas com base em telas do pintor Georges de La Tour.

Tous les matins du monde tem como tema central um músico e sua enorme melancolia por uma perda sem remédio e sem esquecimento: a morte de sua amada, sua mulher, mãe de suas filhas. Assim começa o livro e essa é uma das primeiras imagens do filme, nascidas do relato de Marin Marais, discípulo de Sainte-Colombe, que assim descreve seu mestre:

Na primavera de 1650, Madame de Sainte-Colombe morreu. Ela deixou duas filhas de dois e seis anos. Monsieur de Sainte-Colombe nunca se consolou da morte de sua esposa. Ele a amava. Foi nesta ocasião que ele escreveu "O túmulo das lamúrias"*.

Em Pascal Quignard, a música é marca, destino de sua escrita, lugar de contínua ruminação sobre os mesmos temas: a solidão, o silêncio, a perda de um som, de uma palavra, de algo

${ }^{2} \mathrm{O}$ filme Todas as manhãs do mundo, baseado na obra homônima de Pascal Quignard, foi dirigido por Alain Corneau e tem com intérpretes principais Gérard Depardieu, Jean-Pierre Marielle, Anne Brochet, Guillaume Depardieu e Carole Richert. Pascal Quignard trabalhou na adaptação dos diálogos e no roteiro do filme que ganhou oito prêmios do César 91, a maior premiação do cinema francês. 
nunca mais reencontrado. Talvez seja possível afirmar que, antes da música, haja o silêncio e que esse silêncio seja a ausência de uma voz, de uma determinada voz, a voz materna.

Monsieur de Sainte-Colombe, mudo de dor pela presença de uma ferida mortal na alma, tornou-se cada vez mais taciturno, fechou-se em casa e consagrou-se totalmente à música. A descrição desse homem se estende por várias páginas do romance, construindo-se para o leitor a imagem de um personagem cujo traço mais forte era o silêncio - o silêncio na música; o silêncio, condição da música. Silêncio e música, na figura de SainteColombe; solidão, silêncio e música, em toda a obra de Pascal Quignard, talvez mesmo em sua vida, e talvez por isso Chantal Lapeyre-Desmaison tenha intitulado um de seus livros sobre o autor Pascal Quignard le solitaire*. Impossível separar sua obra de sua vida: lendo sobre uma, a leitura da outra se torna mais rica, mais clara, para o leitor e para o espectador do filme.

Literatura e cinema são sistemas semióticos diferentes, sendo inútil cobrar do segundo fidelidade em relação ao primeiro. É uma tarefa tentadora, todavia, ir atrás das semelhanças e diferenças entre as duas produções e ver como a releitura que é o filme se produz. Nesse caso especial, podemos afirmar que o escritor se relê aí, na adaptação que faz de seu texto para o cinema, tendo trabalhado também em seu roteiro.

A descrição literária de Sainte-Colombe se concretiza de forma surpreendente no ator Jean-Pierre Marielle, que o interpreta: a postura, a voz, o olhar dramatizam a solidão quase selvagem envolvida pelo enorme silêncio que a abriga, a contenção afetiva, a falta de palavras:

O caráter do Senhor de Sainte-Colombe e sua pouca disposição para a linguagem estavam de acordo com seu extremo pudor e seu rosto permanecia inexpressivo e severo diante de qualquer sentimento. Apenas em suas composições seria possível descobrir a complexidade e a delicadeza do mundo escondido sob essa fisionomia e por detrás dos gestos raros e rígidos*.

Imagem e música, o filme Todas as manhãs do mundo enlaça visibilidade e musicalidade, em uma medida diversa do livro, no qual falta essa dimensão em razão da própria natureza da palavra impressa. No livro, entretanto, a música ecoa para o leitor e sua ausência material de certa forma tematiza a voz perdida, a busca de um som para sempre inaudível, mas cuja audição, no filme, torna-se possível em toda sua dramaticidade.

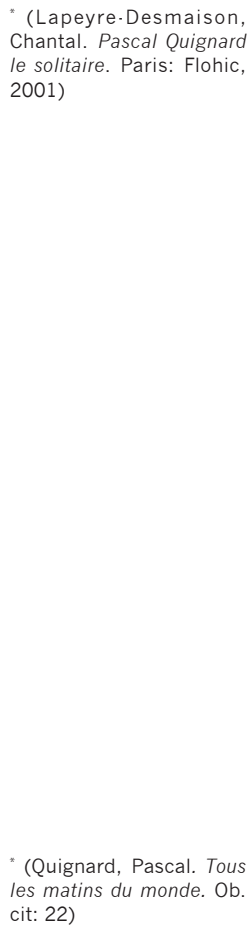

(Quignard, Pascal. Tous les matins du monde. Ob. cit: 22) 
Uma narrativa sobre a música, uma narrativa sobre uma família de três pessoas, um conjunto de três violoncelos: um pai e suas filhas, um trio afinado que faz música, sob a mestria do mestre-músico e sua dor. Percebe-se nesse conjunto de personagens e seus instrumentos uma lógica semiótica, em que o violoncelo é um instrumento musical carregado de grande carga simbólica e densidade emocional, uma vez que tem a ver com a memória da mulher amada e do erotismo vivido com ela por esse marido silencioso, mesmo na alegria.

E o violoncelo circula no tex to, como circula entre as várias mãos, tocado de forma diversa pelos vários dedos, abraçado pelo músico como se abraça o corpo de uma mulher e o amor a ele perdido na morte: perda e música de uma paixão que só fala por meio de suas formas e de seu tato. Não que o silêncio seja uma anterioridade necessária à música, mas é, talvez possamos dizê-lo, sua sombra, seu suplemento.

E esse trio que é uma família e uma orquestra ou, mais adequadamente, um conjunto matemático, musical, é acrescido de um quar to elemento que o descompleta, que o desestabiliza: o jovem músico Marin Marais. Esse jovem Marin Marais, que vem em busca da mestria de Sainte-Colombe, é também ferido, como os membros dessa família, pela perda de uma voz, sua voz infantil, feminina, de cantor do coro de Saint-Germain-l'Auxerrois.

Como já mostrei ao me referir a La haine de la musique, Quignard fala da mudança de voz, que é, para o homem, o acesso à sexualidade e a perda da feminilidade da mãe, da voz materna que o habita visceralmente, na primeira fusão que se dá na carne. Essa nostalgia que faz sofrer Marin Marais é motivo persistente na obra de Pascal Quignard e sem dúvida pode ser lido como repetição da experiência de castração, angústia de castração. Perder a voz da infância equivale a uma ferida na garganta, ferida que tira a voz e arrebata a palavra. E, então, o narrador de Tous les matins du monde revela que Marin Marais dissera a si mesmo que "se vingaria da voz que o havia abandonado, que se tornaria um violoncelista renomado"*.

Mas Sainte-Colombe não acredita que Marais possa ser um músico, pois, para ele, ser músico é uma coisa, e tocar música, outra. Ser músico tem a ver com a radicalidade da solidão, da não-submissão ao outro, seja este o rei ou toda sua corte.

A conquista de uma insociabilidade, de uma liberdade que nada será capaz de invadir ou perturbar, é condição da cons- 
trução de um sujeito e seu desejo. Tal projeto se presentifica na obra de Quignard e em sua vida, configurando-se não como uma idiossincrasia digna de curiosidade, e sim como a própria dignidade do trabalho criador: "Só pertenço a mim mesmo", grita Sainte-Colombe ao representante do rei, que lhe oferece a fama e a riqueza da corte.

Em Sainte-Colombe e Pascal Quignard, exibem-se a mesma necessidade crucial de solidão e de liberdade, a mesma renúncia ao mundo e seus apelos. Então, no lugar dessa solidão, por causa dela, foi possível a Sainte-Colombe criar uma sétima corda para o violoncelo, a fim de ter no instrumento todas as possibilidades da voz humana, da criança, da mulher, do homem, esta última, brisée e tornada grave, quando a criança se torna um homem, encontrando-se assim o adolescente que perdeu a voz, o discípulo e o homem taciturno, seu mestre.

Talvez a questão apresentada pelo livro seja esta: o que é a música, afinal? $\mathrm{O}$ mestre reconhece a destreza de seu discípulo com os instrumentos musicais, mas diz para ele: "Você nunca será um músico”, pois ser músico e tocar música são coisas diferentes, e a música não é feita para agradar ao rei ou ao mundo. O livro é a história do mestre e seu discípulo que teve de descobrir a perda e as lágrimas para se tornar um músico. Isso o mestre não tem como ensinar, embora possa dar algo. E Sainte-Colombe lhe deu as lágrimas com sua obra Le tombeau des regrets - "O túmulo das lamúrias".

O que o romance silencia, pela própria impossibilidade de a palavra fazer música, ser só música, o cinema exibe, fazendo ouvir a música, a beleza extraordinária da música dramática, radical, contundente de Sainte-Colombe. Enquanto no romance a música ecoa no silêncio da letra impressa, no cinema ela se ouve em espetáculo.

Impossível tecer comentários de valor entre os dois códigos, o literário e o cinematográfico, mas na tela Pascal Quignard, que trabalhou na adaptação cinematográfica de seu livro, constrói um espaço de cor, brilho e sombra, semelhante ao que se pode admirar na pintura de Georges de La Tour, sobre o qual ele escreve La nuit et le silence. Neste livro, ele revela que:

[...] houve duas grandes candeias na nossa história e elas se encontram no tempo: as lições das trevas da música barroca, as candeias das telas de Georges de La Tour. Os ofícios das Trevas da Semana Santa constituíam um rito no qual se apagavam uma a uma, durante o canto, as letras hebraicas que formavam o nome de Deus e, uma a 
(Quignard, Pascal. La nuit et le silence. Paris: Flohic, 1997: 9)

(Quignard, Pascal. Les ombres errantes. Paris: Grasset, 2002: 58)

(Quignard, Pascal. Sur le jadis. Ob. cit: 18) uma, graças ao sopro de uma criança vestida de vermelho, as velas que a representavam na obscuridade da agonia* .

Em uma parte extraordinária do filme, em que se representa o ofício das trevas, pode-se notar a presença da pintura de Georges de La Tour como um cenário vivo, com a cor vermelha de suas velas acesas, sopradas por uma criança cantora do coro. Aí se enlaçam, cromática e musicalmente, temas que se desenvolvem discursiva e repetidamente na obra de Quignard: as luzes, as sombras, a música, o silêncio.

Como leitores do livro e espectadores do filme, podemos notar que há uma singular relação entre a página branca e a tela brilhante de luz, pois entre as duas, em um espaço virtual, intervalar, o silêncio, a imagem e a música se tornam paradoxalmente possíveis, em um mesmo tempo, em uma outra lógica, em um outro compasso. Tal efeito só se revela possível por meio de uma dissimetria poética, da qual só podemos falar valendo-nos de uma retórica especulativa, da qual fala Pascal Quignard em seus ensaios e que, parece-me, sustenta a toda sua obra.

Viver no ângulo - in angulo - do mundo é o que parece desejar Quignard em seu livro Les ombres errantes*. Em outro livro, Sur le jadis, da trilogia Dernier royaume, a palavra jadis remete ao tempo do outrora, fonte da escrita: outrora no tempo, aurora do tempo, tempo sem tempo, tempo uterino, aquele que vivemos antes de nascer. Esta é uma das idéias que o obsedam e habitam seu texto de forma intermitente, sem ser pura repetição, mas contínua busca de escrita, que é vida para ele. É o perdido que o avassala, que o faz desejar voltar ao mundo psíquico anterior, no qual a mãe injeta na criança, infans, pela linguagem que planta nela, a língua materna, la langue.

Sobre a atenção pelas pequenas coisas, sons, ruídos, restos de palavras ditas ou murmuradas, Pascal Quignard, aquele que escreveu a vida a partir do silêncio da mãe e desejou um tempo antes do antes, do jadis, afirma:

Acontece que uma mesma seiva libera cada primavera. São as árvores e as flores. Acontece que ninguém que goza é velho. São os fantasmas e os abraços. Acontece, às vezes, que um suco que nunca secou fluidifica sem cessar o tom de uma frase, como a mácula de sangue persiste como poeira na chave do Barba-Azul. O gozo deixa traços. Deixa sapatos de cristal, anéis muito apertados que não servem para ninguém desse mundo*. 
Se estão certos aqueles que afirmam que a escrita feminina tem a delicadeza dos traços, dos fragmentos, dos ritmos e sons em surdina, talvez se sintam reforçados em sua certeza pela afirmação, em tom de confissão, feita por Quignard: "Uma mulher que não está mais aqui está perto de mim e dita calmamente este livro"**.

É possível dizer, sem reduzir e simplificar a obra de Quignard, que ela é uma longa travessia sobre a escrita e o ato de escrever, na solidão do silêncio, com os sons e as cores da aurora, construindo-se como uma maneira de viver.

Experimentar pensando o que procura se dizer, antes mesmo de saber, é, sem dúvida, o movimento de escrever. Por um lado escrever com esse nome na ponta da língua; de outro, com o todo da linguagem que foge sob os dedos. É o que se chama queimar, na aurora da descoberta *.

Finalmente, escrever é escrever o perdido, o indizível e a impossibilidade de captar e recuperar as coisas do outrora, a tentativa de recuperar o primeiro grito, não só as coisas em sua novidade, mas o momento do antes, a palavra aquém da linguagem, as coisas que brotam e que são fonte da linguagem. Ou, em outras palavras: "a linguagem afetada pelo silêncio é o ninho. Como o visível afetado pela obscuridade é o sonho"**.

" (Quignard, Pascal. Les ombres errantes. Ob. cit. 136)

* (: 137) 
Palavras-chave

Pascal Quignard, silêncio,

falta, escrita

Key words

Pascal Quignard, silence,

absence, writing

Mots-clé

Pascal Quignard, silence,

manque, écriture

Recebido em

$31 / 05 / 2005$

Aprovado em

30/06/2005

Ruth Silviano Brandão

Professora de Literatura na UFMG, mestre e doutora em Letras, com pós-Doutorado pela Universidade de Paris VIII. É ensaísta, autora, entre outros, de $A$ mulher escrita, com Lúcia Castello Branco (Lamparina, Rio de Janeiro), Mulher ao pé da letra (UFMG, Belo Horizonte), Literatura e psicanálise(UFRS, Porto Alegre) e A vida escrita (7Letras/Faculdade de Letras/UFMG). É autora também de um romance, de um livro de contos e de poesias. Seu último livro é um conto poético: Aporias de Astérion, publicado pela editora Lamparina. Traduziu O nascimento da poesia: Antonin Artaud, de Jean-Michel Rey, publicado pela Editora Autêntica, Belo Horizonte.

\section{Resumo}

Leitura da obra de Pascal Quignard, partindo-se da noção de fracasso da linguagem, da palavra que falta, daquilo que aponta para o silêncio, para um mutismo que corta a fala, para o aquém da linguagem, e que, no entanto, é causa da escrita.

\section{Abstract}

This is an approach of the work of Pascal Quignard, taking into account the notion of failure of the language; the missing word; and somewhat pointing towards the silence, the mutism that halts the speech, and what lies before the language but, however, is the cause of the writing.

\section{Résumé}

Lecture de l'oeuvre de Pascal Quignard, qui part de la notion d'échec du langage, du mot qui manque, de ce qui conduit vers le silence, vers le mutisme qui coupe la parole, vers l'en deçà du langage et qui, pourtant, est cause de l'écriture. 